\title{
Concern of Photosensitive Seizures Evoked by 3D Video Displays or Virtual Reality Headsets in Children: Current Perspective
}

This article was published in the following Dove Press journal: Eye and Brain

\author{
Lawrence Tychsen ${ }^{1-3}$ \\ Liu Lin Thio ${ }^{2-4}$ \\ 'Department of Ophthalmology and \\ Visual Sciences, ${ }^{2}$ Department of \\ Pediatrics, ${ }^{3}$ Department of \\ Neuroscience, ${ }^{4}$ Department of \\ Neurology, St. Louis Children's Hospital, \\ Washington University in St. Louis School \\ of Medicine, St. Louis, MO, USA
}

\begin{abstract}
This review assesses the risk of a photic-induced seizure in a child during viewing of 3D (binocular 3 dimensional, stereoscopic) movies or games, either on standard video displays or when wearing a virtual reality (VR) headset. Studies published by pediatric epilepsy experts emphasize the low risk of 3D viewing even for children with known photosensitive epilepsy (PSE). The low incidence of PSE is noteworthy because the number of hours devoted to $2 \mathrm{D}$ or 3D screen viewing and/or VR headset use by children worldwide has increased markedly over the last decade. The medical literature does not support the notion that VR headset use poses a risk for PSE.
\end{abstract}

Keywords: virtual reality, epilepsy, stereoscopic, children

\section{Photosensitive Epilepsy (PSE) Clinical Features and Risk Factors}

A seizure is a single occurrence, whereas epilepsy connotes two or more seizures. The prevalence of photosensitive epilepsy (PSE) is estimated to be $0.03 \%$ of the population, ${ }^{2,3}$ with an incidence of $0.002 \%$. Prevalence is the proportion of a population with a given disease at a specified time. Incidence is the proportion of new cases of a disease in a population per unit time, eg, in a given year. ${ }^{4}$ Those at greatest risk for PSE are children aged 7-19 years. ${ }^{4}$ The term photosensitive epilepsy is entrenched in the neurological literature. Alternatively, single seizures evoked by visual stimuli may be termed photoconvulsive response. ${ }^{1}$

PSE is the most common of the reflex epilepsies and consists of seizures provoked by photic stimuli such as flickering lights. ${ }^{5,6}$ Children with a generalized epilepsy are more likely to have PSE, though those with a focal epilepsy, especially an occipital epilepsy, can also have a PSE. ${ }^{3,6}$ Photic-induced seizures include generalized tonic-clonic, absence, and myoclonic seizures with myoclonic the most common. ${ }^{6}$ Photic-induced myoclonic seizures are a prominent feature of eyelid myoclonia with absence epilepsy (Jeavon syndrome) as well as progressive myoclonic epilepsy. ${ }^{3,6}$ The most evocative stimulus is high contrast, bright (high luminance) light flashed across the entire field of vision at 15-25 cycles per second $(\mathrm{Hz}){ }^{7}$ A red flicker (of wavelength $660-720 \mathrm{n} \mathrm{m}$ ) is more likely to induce a seizure than a blue or white one. ${ }^{7,8}$ Repetitive flashing of high-contrast bar and checkerboard patterns provoke seizures in some individuals with PSE. Reducing stimulus luminance and contrast decreases substantially the risk of PSE. Individuals with PSE are therefore
Correspondence: Lawrence Tychsen St. Louis Children's Hospital, Washington University Medical Center, One Children's Place, Suite 3II0, St. Louis, MO 63II0, USA

Tel +I 3144542125

Email tychsen@wustl.edu 
instructed - in the presence of evocative stimuli - to close one eye (monocular viewing reduces the photic stimulus by $50 \%$ ), to wear sunglasses and/or to increase background room illumination (reducing contrast). The risks of PSE, as with all types of epilepsy, are increased by sleep deprivation and illness. ${ }^{7}$

The excitability of visual cortex is known to vary with stimulus contrast, luminance, and temporal frequency. Patients with PSE have abnormally large-amplitude visually-evoked responses to high-luminance, highcontrast patterns (black-and-white gratings). ${ }^{9}$ In normal subjects, electrical stimulation of the scalp overlying the visual cortex gives rise to sensations of flickering light (phosphenes). ${ }^{10}$ The phosphenes are most impressive when the field of vision is illuminated and the electrical current is oscillated at $12-25 \mathrm{~Hz}$. The phosphenes are $50 \%$ weaker when the current is applied in total darkness.

\section{PSE Confusion with Photoparoxysmal Response}

The clinical test for suspected PSE is to record brain electrical activity by electroencephalography (EEG) in the presence of intermittent photic stimulation (IPS). Electrodes are placed across the scalp and an EEG is recorded with the test subject viewing a stroboscopic (flashing 1-60 Hz) round lamp (light intensity $\geq 0.7$ joules, extremely bright) held $30 \mathrm{~cm}$ from the eyes in a dim room. ${ }^{7,11}$ The duration of IPS should be $\geq 10 \mathrm{~s}$. An abnormal EEG response to IPS consists of spikes, spikewaves, or intermittent slow waves, which may be generalized or limited to the anterior or posterior areas of the brain. ${ }^{7}$ These abnormal EEG responses are called a photoparoxysmal response (PPR) if the spikes are not confined to the posterior area. $^{7}$ About $5-10 \%$ of adults and $10-20 \%$ of children with epilepsy have a PPR with the highest prevalence in children aged 7-19 years. ${ }^{4}$ Patients with a generalized epilepsy are more likely to have a PPR than those with a focal epilepsy. Children with juvenile myoclonic epilepsy having the highest prevalence (17-30\%). ${ }^{3,11}$ PPR is twice as common in epileptic females as compared to epileptic males. ${ }^{7,11}$

PPR should not be mistaken for PSE (discussions in the literature may conflate PPR with PSE). PPR is an abnormal EEG response but not necessarily a seizure. The distinction is important because large scale, EEGbased screening studies of normal children and young adults yield prevalence and incidence numbers for PPR that are substantially greater than those for PSE. In normal male school children, PPR was found in $1.3 \%$ and in populations of healthy young teenagers and young adults in their early $20 \mathrm{~s}$ the prevalence ranged from $0.35 \%$ to $7.5 \%{ }^{3,11}$ Only $3 \%$ of these individuals developed epilepsy when followed to the age of 20 years. $^{3}$

\section{Reports of PSE Evoked by Television and Video Games}

In 1992 concerns appeared of possible seizures evoked by the Nintendo video game Mario World. Several pediatric neurological studies published in 1994 devoted to this possibility reported small series of children who may have had video-game-related seizures. In almost all cases, the children involved had established epilepsy. To assess the general population risk Quirk et $\mathrm{al}^{12}$ surveyed EEG neurology clinics for photosensitive seizure events that may have been linked to video game play. The surveyed encompassed $90 \%$ of the EEGs performed throughout Great Britain. Based on the presence of EEG PPR Quirk et al concluded that a very small number of children aged 9-17 years likely had a video game-related first seizure. But $40 \%$ or more of these children had the chance occurrence of two statistically unrelated events: playing electronic screen games and the general incidence of childhood epilepsy. Quirk et al calculated that the population wide risk of a first seizure induced by video game play was $1.5 / 100,000$ or an incidence of $0.002 \%$. The low incidence is noteworthy because the number of hours devoted to electronic screen viewing by children worldwide has increased markedly over the last decades.

On December 16, 1997, some 7 million Japanese children were estimated to be watching a Pocket Monster (Pokémon) cartoon on standard 2D $(50-60 \mathrm{~Hz})$ television screens containing a rocket launch sequence. The sequence in question consisted of a flashing $(12.5 \mathrm{~Hz})$ high-contrast red-and-blue screen that persisted for $4 \mathrm{~s}$. Of the 7 million, 685 were taken to hospitals for evaluation of what was believed to be a seizure. Of the 685 children, 150 were admitted to hospitals for observation. ${ }^{13}$ If we assume for the sake of argument that all 150 admitted to hospitals had a true seizure the prevalence was $150 / 7,000,000$ or $0.002 \%$. To place this in perspective, the seizure rate was 15 -fold lower than the estimated $0.03 \%$ prevalence of PSE in the population., ${ }^{2,3}$

Some of the children may have had a pseudo-seizure, eg, visually induced motion sickness, visual distortions, migraines or other non-seizure phenomena. ${ }^{711}$ Nevertheless, an analysis of children (age 6-18 years old) presenting to a hospital in the 
Aichi prefecture for symptoms associated with viewing the Pocket Monster cartoon concluded that $98 \%$ had a seizure. ${ }^{14}$ The estimated incidence of seizures evoked by the cartoon in the Aichi prefecture was $0.02 \%,{ }^{14}$ equivalent to the estimated incidence of PSE in the population. ${ }^{4}$ The majority of these children (75\%) had no prior history of epilepsy. As expected with PSE, only a minority of the children $(27 \%)$ had a seizure recurrence within 5 years. ${ }^{15}$

A rare subtype of PSE evoked predominantly by $50-60$ $\mathrm{Hz}$ TV and video screens (circa 1995) is photosensitive occipital lobe epilepsy, which shares features of classical migraine. ${ }^{16}$ Classical migraine is characterized by fortification scotomata (jagged flashing lines across a portion of the field of vision), epigastric discomfort, and headache. Occipital lobe epilepsy shares these features but is distinguished by: 1) PPR during EEG recording, absent in patients who suffer classical migraine; and 2) a history of repeated manifestation of the symptoms when exposed to $50-60 \mathrm{~Hz}$ video screen viewing.

In 2010, Harding published criteria which were subsequently developed as an automatic (software) test for PSEprovocative image sequences in video content. The Harding Flash and Pattern Analyzer (FPA) detects prolonged flash sequences with high contrast, high-luminance colors. Video sequences in games or TV shows that register as high risk are then modified to reduce or eliminate the provocative features.

\section{Concerns of PSE Evoked by 3D Television Displays}

A study in $2012^{17}$ examined the risk of PSE in 150 children (mean age 12 years) while watching 15 mins of $3 \mathrm{D}$ video from the film Ice Age 3. The children wore 3D shutter glasses to view the video on a 50 -inch $3 \mathrm{D}$ plasma TV during EEG recording. One half of the children (56\%) were being treated for epilepsy and the other half (44\%) had other neurological conditions such as headache. During viewing, none of the 150 children had PSE. Three of the children with epilepsy (3/84 or $4 \%$ ) had more than a doubling of epileptiform discharges but did not have any clinical symptoms or EEG seizures.

A neurological review published in $2012^{18}$ concluded that in children with known PSE the risk of triggering a seizure was no greater watching 3D TV or cinema than when watching conventional TV. The only caution was that $3 \mathrm{D}$ shutter glasses should not be worn by children who have PSE if they switch to watching a $2 \mathrm{D}$ movie (the shutter glasses evoke noticeable image flicker if worn inadvertently during 2D viewing).

\section{PSE and VR Headsets}

A search of the medical literature (PubMed Central) revealed no reports of PSE evoked by VR headset viewing. One might expect enhanced reports of PSE with VR headsets because: a) a wide expanse of the visual field is filled by the video image ( $>100 \mathrm{deg}), \mathrm{b})$ ambient room illumination is eliminated by the headset surround (increasing relative screen contrast), and c) the brightness and contrast of the organic-light-emitting-diode (OLED) display is greater than with older cathode-ray tube (CRT) TV screens. Reduced risk of PSE with VR headsets may be expected given the substantially increased refresh rates (90 Hz, eg, HTC Vive, Oculus Rift, and Sony PlayStation VR) compared to older TV and video displays. Of note, the Samsung Gear VR Headset has a refresh rate of only 60 $\mathrm{Hz}$ but no reports of PSE with its use have been reported.

As an example of cautions published by VR Headset suppliers, Oculus lists in their Health and Safety Warnings the following:

Seizures: Some people (about 1 in 4000) may have severe dizziness, epileptic seizures or blackouts triggered by light flashes or patterns, and this may occur while they are watching TV, playing video games or experiencing virtual reality, even if they have never had a seizure or blackout before or have no history of seizures or epilepsy. Such seizures are more common in children and young people under the age of 20. Anyone who has had a seizure, loss of awareness, or other symptom linked to an epileptic condition should see a doctor before using the headset.

\section{St Louis Children's Hospital/ Washington University Medical Center Pediatric Epilepsy Advice}

The pediatric neurologists of the Children's Hospital Epilepsy Clinic do not restrict viewing of 3D movies or games, or VR headset play in children with epilepsy or children with known PSE or PPR elicited during EEG recording. Their opinion is that epileptic children should be encouraged to engage in normal peer activities, including all types of video viewing or play. None that we queried reported encountering a child who had PSE induced by $3 \mathrm{D}$ viewing or VR headset play. In our Washington University study of neurologically normal children (50 children aged 4-10 years) we have found no 
evidence of any untoward effect of Sony PlayStation VR headset $3 \mathrm{D}$ video game viewing for cumulative durations of $1 \mathrm{hr}$ or more. ${ }^{19}$

\section{Disclosure}

LLT reports consulting fees for work done via the Epilepsy Study Consortium from Eisai Inc, GW Pharmaceuticals, Takeda Pharmaceuticals, and Zogenix, outside the submitted work. The authors report no other conflicts of interest in this work.

\section{References}

1. Kasteleijn-Nolst Trenité DG, Hirsch E, Reed RC, Abou-Khalil B, Schmidt B. Comment from Dorothée G.A. Kasteleijn-Nolst Trenité, Edouard Hirsch, Ronald C. Reed, Bassel Abou-Khalil, and Bernd Schmidt on: how predictive are photosensitive epilepsy models as proof of principle trials for epilepsy. Seizure. 2014;23(10):922-923.

2. Harding G. Photosensitivity: a vestigial echo? The first Grey Walter lecture. Int J Psychophysiol. 1994;16(2-3):273-279. doi:10.1016/ 0167-8760(89)90054-8

3. Martins da Silva A, Leal B. Photosensitivity and epilepsy: current concepts and perspectives-A narrative review. Seizure. 2017;50: 50209-50218.

4. Quirk JA, Fish DR, Smith SJ, Sander JW, Shorvon SD, Allen PJ. Incidence of photosensitive epilepsy: a prospective national study. Electroencephalogr Clin Neurophysiol. 1995;95(4):260-267. doi:10.1016/0013-4694(95)00118-I

5. Fisher RS, Acevedo C, Arzimanoglou A, et al. ILAE official report: a practical clinical definition of epilepsy. Epilepsia. 2014;55 (4):475-482. doi:10.1111/epi.12550

6. Padmanaban V, Inati S, Ksendzovsky A, Zaghloul K. Clinical advances in photosensitive epilepsy. Brain Res. 2019;170:318-325.

7. Fisher RS, Harding G, Erba G, Barkley GL, Wilkins A, Epilepsy FOAWG. Photic- and pattern-induced seizures: a review for the Epilepsy Foundation of America Working Group. Epilepsia. 2005;46(9):1426-1441. doi:10. 1111/j.1528-1167.2005.31405.x
8. Takahashi Y, Ozawa T, Nakamura H, et al. Long-wavelength red light emission from TV and photosensitive seizures. Acta Neurol Scand. 2001;103(2):114-119. doi:10.1034/j.1600-0404.2001.103002114.x

9. Porciatti V, Bonanni P, Fiorentini A, Guerrini R. Lack of cortical contrast gain control in human photosensitive epilepsy. Nat Neurosci. 2000;3:259-263.

10. Kanai R, Chaieb L, Antal A, Walsh V, Paulus W. Frequencydependent electrical stimulation of the visual cortex. Curr Biol. 2008;18(23):1839-1843. doi:10.1016/j.cub.2008.10.027

11. Verrotti A, Beccaria F, Fiori F, Montagnini A, Capovilla G. Photosensitivity: epidemiology, genetics, clinical manifestations, assessment, and management. Epileptic Disord. 2012;14(4):349-362. doi:10. 1684/epd.2012.0539

12. Quirk JA, Fish DR, Smith SJ, Sander JW, Shorvon SD, Allen PJ. First seizures associated with playing electronic screen games: a community-based study in Great Britain. Ann Neurol. 1995;37 (6):733-737. doi:10.1002/ana.410370606

13. Ishida S, Yamashita Y, Matsuishi T, et al. Photosensitive seizures provoked while viewing "pocket monsters," a made-for-television animation program in Japan. Epilepsia. 1998;39(12):1340-1344. doi:10.1111/j.1528-1157.1998.tb01334.x

14. Takada H, Aso K, Watanabe K, Okumura A, Negoro T, Ishikawa T. Epileptic seizures induced by animated cartoon, "Pocket Monster". Epilepsia. 1999;40(7):997-1002. doi:10.1111/epi.1999.40.issue-7

15. Okumura A, Watanabe K, Negoro T, et al. Epilepsies after pocket monster seizures. Epilepsia. 2005;46(6):980-982. doi:10.1111/epi.2005.46.issue-6

16. Guerrini R, Dravet C, Genton P, et al. Idiopathic photosensitive occipital lobe epilepsy. Epilepsia. 1995;36(9):883-891. doi:10.1111/ epi.1995.36.issue-9

17. Kluger G. How safe is 3D TV for children with epilepsy? Neurol Rev. 2012;20(3):5.

18. Prasad M, Arora M, Abu-Arafeh I, Harding G. 3D movies and risk of seizures in patients with photosensitive epilepsy. Seizure. 2012;21 (1):49-50. doi:10.1016/j.seizure.2011.08.012

19. Tychsen L, Foeller P. Effects of immersive virtual reality headset viewing on young children: visuomotor function, postural stability and motion sickness. Am J Ophthalmol. 2020 Jan;209:151-159. doi:10.1016/j.ajo.2019.07.020
Eye and Brain

\section{Publish your work in this journal}

Eye and Brain is an international, peer-reviewed, open access journal focusing on clinical and experimental research in the field of neuroophthalmology. All aspects of patient care are addressed within the journal as well as basic research. Papers covering original research, basic science, clinical and epidemiological studies, reviews and

Submit your manuscript here: https://www.dovepress.com/eye-and-brain-journa evaluations, guidelines, expert opinion and commentary, case reports and extended reports are welcome. The manuscript management system is completely online and includes a very quick and fair peerreview system, which is all easy to use. Visit http://www.dovepress. com/testimonials.php to read real quotes from published authors. 